\title{
$\$$ Research Square

\section{Intimate Partner Violence and Mental Health Within the Community During Lockdown of Covid-19 Pandemic}

Fabienne Glowacz ( $\square$ Fabienne.glowacz@uliege.be )

University of Liège

Emilie Schmits

University of Liège

Amandine Dziewa

University of Liège

\section{Research Article}

Keywords: Intimate partner violence, COVID-19 Pandemic, depression, anxiety, Uncertainty

Posted Date: April 29th, 2021

DOI: https://doi.org/10.21203/rs.3.rs-418428/v1

License: (c) (i) This work is licensed under a Creative Commons Attribution 4.0 International License.

Read Full License 
Intimate partner violence and mental health within the community during lockdown of covid-19 pandemic

\section{Keywords: Intimate partner violence, COVID-19 Pandemic, depression, anxiety,}

\section{Uncertainty.}

Fabienne GLOWACZ ${ }^{1 *}$, Emilie SCHMITS ${ }^{2}$, Amandine DZIEWA $^{3}$

${ }^{1}$ Department of Psychology - Adaptation, Resilience and Change Research Unit (ARCh) University of Liège- Place des Orateurs, 1-Liège, Belgium fabienne.glowacz@uliege.be

${ }^{2}$ Department of Psychology - Adaptation, Resilience and Change Research Unit (ARCh) University of Liège Place des Orateurs, 1- Liège, Belgium Emilie.Schmits@uliege.be

${ }^{3}$ Department of Psychology -Adaptation, Resilience and Change Research Unit (ARCh) Universiy of Liège, Place des Orateurs, 1- Liège, Belgium Amandine.Dziewa@uliege.be Correspondence to Fabienne Glowacz : fabienne.glowacz@uliege.be

\section{Abstract}

Background: This study took place in the context of the COVID-19 pandemic. The restrictive confinement measures put in place to counter the virus' spread could have major consequences for the mental health and intimate relationships between romantic partners. The present research assesses the association between lockdown conditions (such as time spent at home, living environment, proximity to contamination and social contacts), mental health (including intolerance of uncertainty, anxiety and depression) and the intimate partner violence within the community. This study also proposes to evaluate the indirect effect of anxiety and depression on the relationship between intolerance of uncertainty and intimate partner violence (physical assault and psychological aggression). Methods: 1532 adults ( $80.8 \%$ of women, $\left.\mathrm{M}_{\mathrm{age}}=35.34\right)$ were recruited from the general population through an online self-report questionnaire completed during the lockdown. All participants were engaged in a romantic relationship and lived with their partner. Sociodemographic data, lockdown conditions, mental health and 
intimate partner related-variables were assessed. Results: Results demonstrate that the prevalence of physical assault was significantly higher in men, whereas the prevalence of psychological aggression was significantly higher in women. Men reported significantly more increased violence during lockdown. Women, on the other hand, were more anxious and more intolerant of uncertainty. No difference between men and women was found for depression. Anxiety and depression significantly mediate the relationship between intolerance of uncertainty and physical assault and psychological aggression. Sex does not moderate the mediation. Conclusion: Clinical implications for public health policy are highlighted, namely the necessity to consider the impact of uncertainty related to crises in increasing the risk of intimate violence between partners, and especially individual vulnerability to mental health problems associated.

\section{Introduction}

On March 11, 2020, the WHO declared the COVID-19 outbreak a pandemic as the virus spread worldwide. One of the disturbing features of an emerging epidemic is that, as long as the precise cause and evolution are unknown, the uncertainty engendered by the situation can increase the level of psychosocial morbidity $[1,2,3,4,5,6]$. In an attempt to control this pandemic, governments across the world have taken action through restrictive measures unprecedented in the history of public health, such as lockdowns, social distancing and voluntary self-isolation $[7,8,9,10]$. These restrictive confinement measures put in place to counter the virus' spread could have major consequences for the mental health. Indeed, several studies conducted in China and in Europe, have reported high levels of depressive and anxiety symptoms as well as poor sleep quality, and younger people have reported a significantly higher prevalence of generalized anxiety disorder and depression $[7,9,10,11,12,13,14,15]$. Furthermore, the restrictive measures are likely to increase the risk of family violence and reduce options for support [16]. Being confined to one's home can lead to tension and violence in couples where 
there was previously no violence, as well as increase the incidence of violence. In fact, social distancing and the orders to stay at home could lead to an increase in conflicts, disagreements and arguments, due to the increased daily proximity of couples but also by the limitation or absence of access to other social and public spaces (professional, recreational, sports,...) that contribute to the regulation of tensions and to the well-being of people. Moreover, other factors such as economic uncertainty, job loss, and being with children all the time may add to the stress experienced by both women and men, thereby increasing the risk of marital conflict and violence [17]. In addition, confinement may reinforce or facilitate control, surveillance and coercion strategies of perpetrators of intimate partner violence [18, 19]. A number of experts have warned that women would be increasingly exposed to IPV in a lockdown situation. In fact, a rise in reports of domestic abuse, in the number of calls from victims in distress, and demand for support has been noted in many countries, including in Belgium [18, 20].

In this way, the COVID-19 pandemic has revealed how IPV remains a major societal and health problem [16, 21]. The risk of IPV was considered and guided public policy. Governments faced with the risk of IPV have encouraged either the violence reporting or the reception of victims during the lockdown. Pharmacies and grocery stores in France and Belgium have been provided emergency warning systems to allow people to indicate that they are in danger and need support through the use of code words to alert staff $[22,23]$.

While research on domestic violence prevention and treatment is ongoing and several sources have speculated on the impact COVID-19 has had on it [16, 21, 24], an increasing number of published peer-reviewed studies are analyzing IPV rates in light of the pandemic $[25,26,27]$. The main objective of this study is to assess, based on an online survey, the presence of IPV during the period of confinement, the associated factors related to lockdown and the pandemic and to mental health individual vulnerabilities. 


\section{Intimate partner violence}

In recent years, intimate partner violence has been recognized as a real social and public health problem and has become a central issue on the European political agenda. IPV includes acts of physical and sexual violence, emotional-psychological abuse, and controlling behaviors toward intimate partners of the same or opposite sex [28, 29, 30, 31, 32]. According to Johnson's typology of IPV, there are two prevalent forms of IPV: intimate terrorism (IT) and situational couple violence (SCV). Intimate terrorism is part of a cyclical dynamic in which the abuser uses a variety of strategies (violent and non-violent) to control and terrorize his partner, including psychological, physical and sexual abuse, as well as intimidation and threats. The perpetrators of this violence (IT) are mostly men, which can be explained by the fact that it is rooted in patriarchy. Situational couple violence represents the violence that emerges when a conflict escalates into violence. While conflict is present in all couples, for some couples, these conflicts increase in frequency and intensity, culminating in the perpetration of violent acts $[33,34]$. The different studies have shown that situational couple violence the most represented in general surveys, whereas intimate terrorism and violent resistance dominate in agency samples, and this is a source of difference across studies with respect to the gender symmetry of partner violence $[35,36,37]$. Our study focuses both on forms of physical and psychological violence. Physical violence involves forceful physical contact that may vary from light pushes and slaps to severe beatings and lethal violence [31].The term psychological aggression refers to acting in an offensive or degrading manner toward another, usually verbally, and may include threats, ridicule, withholding affection, and restrictions (e.g., social isolation, financial control) . One of the most frequent forms of IPV in western societies is psychological. It can occur either in isolation or in conjunction with other forms of IPV and can be bidirectional [32, 38, 39, 40, 41]. Several studies and meta-analyses have identified poor mental health, including depression and anxiety, as one of the risk factors for physical and psychological violence and it is associated 
with victimization and perpetration by both women and men [42, 43, 44, 45, 46]. However, this association may vary by gender and type of IPV [47]. Overall, symptoms of anxiety and depression were recognized as very high during the pandemic containment period $[7,9,10,11$, 12]. Various studies have estimated the effects of the COVID-19 pandemic on mental health and have linked financial stress, food insecurity, fear of infection and increased time spent with a partner to increased stress. Stress, frustration and the lack of control can exacerbate the psychopathological problems associated with IPV, further precipitating violent episodes. Situations that increase stress appear to be one of the important risk factors for victims of partner violence $[26,48,49]$.

\section{Intolerance of uncertainty}

The Covid 19 pandemic is dominated by significant uncertainties about the virus and how to control it and the variants, more globally in relation to the unpredictability of the future [50]. In this context, distress related to uncertainty is an understandable reaction and even appropriate reaction. However, if the threat and uncertainty becomes pervasive, it can disrupt the psychological and social functioning of the individual [4]. In this regard, intolerance of uncertainty (IU) refers to individual differences in the difficulties of coping with the experience of uncertainty. IU can result in a range of cognitive, emotional, and behavioral responses aimed at avoiding and/or resolving the aversive experience [51, 52]. Thus, the inability to deal with distress arising from uncertain situations can have a detrimental effect on mental health, leading to various psychopathological symptoms, such as anxiety or depression $[54,55]$. Very recent research has shown that COVID-19-related IU played a fundamental role in psychopathological symptoms (depression and anxiety) in the population during confinement $[56,57,9]$. IU may also be implicated in maladaptive externalizing behaviors and diagnoses [51]. Distress resulting from elevated UI could, in turn, increase the propensity for aggressive behavior in some individuals [58]. However, few studies have investigated the role of IU in aggressive behavior 
and violence and none have done so in the highly anxiety-provoking context of a pandemic crisis. Nevertheless, one study has shown the links between IU and anger/aggression [59]. Moreover, the risk for the externalizing spectrum of psychopathology related to difficulties in tolerating uncertainty may lead individuals to engage in risky behaviors to alleviate distressing or unpleasant emotions [60]. No studies, to our knowledge, have dealt with IU and IPV. However, with feelings of uncertainty being particularly prevalent during an emerging pandemic, our study will integrate the variable IU in order to evaluate its links with violence between partners. Anxiety and depressive symptoms will be examined in our study as predictors of IPV, and as well as mediator, in particular, intolerance of uncertainty.

\section{Our study}

Carried out within during the COVID-19 pandemic, the main purpose of this study is to first assess the association between "proximal factors" related to confinement and IPV within the community: lockdown conditions, such as time spent at home, the living environment, the frequency of social contact through digital media, proximity to contamination, and the intolerance of uncertainty and the mental health (anxiety and depression). Second, the roles intolerance of uncertainty, anxiety and depression have played in the increase of IPV cases during the pandemic crisis will be considered.

Finally, as the literature highlights that intolerance of uncertainty could implicate anxiety and depressive disorders $[2,61,62,63]$ and that these mental health problems could be risk factors for violence $[42,43,44,45,46]$, the present study also proposes to assess the indirect effects of anxiety and depression on the relationship between intolerance of uncertainty and intimate partner violence. Mental health-related variables mediate the predictive effect of IU on IPV (mediation model) differently among men and women (moderated mediation model). Physical assault and psychological aggression will also be considered separately. 


\section{Methods}

\subsection{Participants}

1,532 adults $(80.8 \%$ women, $\mathrm{n}=1237)$ were recruited from the general population through an online self-report questionnaire. All participants were engaged in a romantic relationship and lived together. They were aged between 18 and 83 years $(M=35.94, S D=14.84) .82 .6 \%$ $(n=1265)$ of participants lived in Belgium, 17.4\% $(n=266)$ in another French-speaking country (mainly France and Canada). More than $80 \%(n=1225)$ were graduates of higher education. $3.8 \%(\mathrm{n}=58)$ were in a same-sex relationship. The duration of the relationships were distributed as follows: $2.1 \%(n=32)$ less than 6 months, $11.1 \%(n=170)$ between 6 months and 2 years, $35.6 \%(n=545)$ between 2 and 10 years, $25.5 \%(n=391)$ between 10 and 20 years, and $25.7 \%$ $(n=394)$ more than 20 years. $58 \%(n=888)$ of participants had children, but only $46.7 \%(n=715)$ were living with children during the lockdown. As of the lockdown, 46.4\% ( $n=711)$ were working from home, $25.1 \%(n=384)$ were taking time off or were out of work, $14.9 \%(n=229)$ were working at their workplace, and $13.6 \%(n=208)$ were students. $23.8 \%(n=364)$ of the participants had lost some financial income. In the present sample, $12.5 \%(n=191)$ thought that they had been infected by the coronavirus but had not been tested, less than $1 \%(n=10)$ had tested positive for the coronavirus, and $86.9 \%(\mathrm{n}=1331)$ reported that they had not been infected by the coronavirus. Also, $19.6 \%(n=300)$ believed that one person close to them had been infected but not tested, $11.3 \%(\mathrm{n}=173)$ knew one person close to them who had tested positive, and $69.1 \%(n=1059)$ believed that none have been contaminated. Finally, 6.3\% $(n=96)$ of the sample had consulted a psychologist during the lockdown.

\subsection{Materials and measures}

This research consisted of a Web-based electronic survey, including simple random sampling methods of recruitment. Invitations to participate was broadly and non-selectively sent by email 
to the general population, as well as posted at multiple online places. The experimental protocol complied with the Belgian guidelines for studies involving human beings and was approved by the IRB of the University of Liège. The data collection was conducted in accordance with the Helsinki Declaration. Data were obtained through this online self-report questionnaire distributed one month after the beginning - in other words, just before the end of the lockdown - during the period from April 17 to May 1, 2020. We complied with ethical research standards in providing information about the project and asking for consent to participate in the online survey. All respondents provided informed consent. In order to answer any question or to deal with any inconvenience caused by scales (feelings of discomfort or distress or danger), the researcher's e-mail address was given at the beginning and at end of the questionnaire and a videoconference meeting with a specialized psychologist in the field of domestic violence was offered free of charge.

2.2.1. Sociodemographic data and lockdown conditions. These data are part of a large database collected during lockdown related to the COVID-19 crisis [9]. It includes the usual sociodemographic data (gender, age, country of residence, educational background and marital status), data on lockdown conditions were collected: children and their presence during this period (dichotomous variables: Yes/No), professional situation during the lockdown (including four categories: student, working from home, usual workplace, no work), time spent at home (a score ranging from 0 , working out of home during the day, to 2 , at home without work all the day), living environment (a score ranging from one to eight evaluating the surface area of the accommodation as well as the availability of a terrace and a garden) and loss of financial income (dichotomous variable: Yes/no). The frequency of social contact was also assessed through 7 items on a 4-points Likert scale from ( 1 = never; 4 = everyday $)$ evaluating contact with friends, family, colleagues and so on through digital media. A high score indicates a high frequency of social contact through digital media. The primary (oneself) and secondary (a close person) 
coronavirus contaminations were specified (three modalities: not infected, infected but not tested, tested positive for the coronavirus). On this basis, a score of proximity to contamination was determined, including a gradual score from 0 (neither the person himself, nor a loved one, was infected) to 8 (the person himself and a loved one had tested positive for the coronavirus). A high score indicates a high level of proximity to contamination.

2.2.2. Mental health-related variables. Anxiety and depression were evaluated by the two subscales of the Hospital Anxiety and Depression scale (HAD) [64]. The HAD is a 14 item scale that proposes seven items related to anxiety (in the present sample, $\alpha=.80$ ) and seven related to depression (in the present sample, $\alpha=.68$ ), scoring from 0 to 3 . Cut-off points of 8 and 11 have been identified [65]. Two items of the Intolerance of Uncertainty Scale (IUS) [52] have been included to evaluate reactions to uncertain situations (in the present sample, $\alpha=.72$ ), scoring from 1 (not at all corresponding) to 5 (extremely corresponding). An additional item, also scoring from 1 (not at all corresponding) to 5 (extremely corresponding), has been created, namely “Uncertainty makes me more aggressive with my partner in terms of my words, gestures and attitudes" (named "Uncertainty-related aggression"). Finally, a question evaluating if the person had consulted a psychologist (through a videoconferencing system) during the lockdown (dichotomous: Yes/No) was also included.

2.2.3. Intimate partner related-variables. The length of the romantic relationship was assessed through a question with 5 modalities (from less than 6 months to more than 20 years). The higher the score, the longer the relationship. The 20-question short-form Revised Conflict Tactic Scales (CTS2S) [66] was used to measure intimate partner violence. The instruction and quotation were adapted to the context of the lockdown period. Three types of IPV were identified (physical assault, psychological aggression, and sexual coercion) as well as an emotional and psychological negotiation. Only physical assault (e.g., pushing, kicking, beatingsprains and bruises) and psychological aggression (e.g. yelling, arguing, threatening harm and 
destroying belongings) in the relationship will be considered in the present research (respectively, $\alpha=.73$ and .63). An additional question (subjective self-evaluation) on the evolution of violence has been included, with 4 modalities of answer (No violence, decreased violence, continuing violence, increased violence).

\subsection{Data analysis}

SPSS 26 software was used to perform the statistical analyses. Descriptive statistics, consistency reliability, Spearman's correlations, Chi-square (with Phi coefficient) and MannWhitney $\mathrm{U}$ tests were conducted. Statistical significance was set at $\mathrm{p}<0.05$. To test mediation and moderated mediation hypotheses, PROCESS modeling, as outlined by Preacher and Hayes 67], was applied and a bootstrapping method (10 000 bootstrap samples) was used. This method is a nonparametric approach to effect-size estimation and hypothesis testing that is not based on large-sample theory and, therefore, circumvents the power problem associated with asymmetries [68]. When zero is not included in the bootstrap confidence intervals, it is possible to set a significant indirect effect (mediator effect) or conditional effect (moderator effect) reflected in the Index of moderated mediation $[69,70,71]-$ at $p<.05$. Tested models are shown in figure 1.

Figure 1. Moderated mediation models.

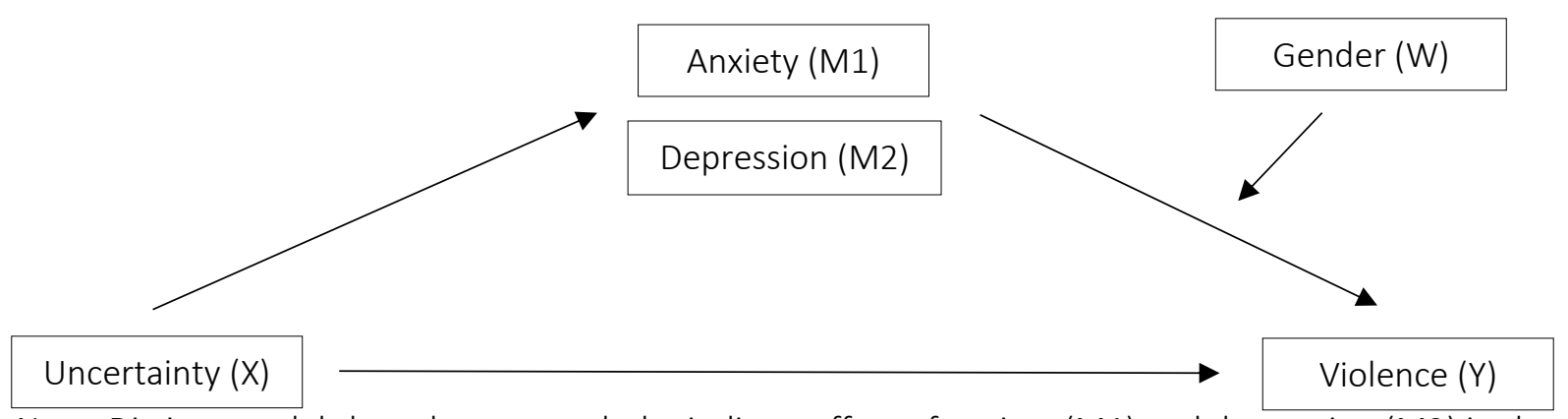

Note. Distinct models have been tested: the indirect effect of anxiety (M1) and depression (M2) in the relationship between intolerance of uncertainty $(X)$ and physical (model 1 ) and psychological (model 2) violence $(Y)$, according to gender $(W)$ (model 3 and model 4 ).

\section{Results}




\subsection{Descriptive statistics and correlations}

245 The first results show prevalence rates concerning intimate partner violence. Among the 246 subsample of perpetrators of intimate partner violence (33.4\% of the total sample, $\mathrm{n}=511)$, $24784.5 \%(n=432)$ are also victims of violence. Among the subsample of victims of intimate 248 partner violence ( $28.2 \%$ of the total sample, $\mathrm{n}=432), 100 \%$ are also perpetrators. In other words, among the total sample $(n=1532), 28.2 \%$ are both perpetrators and victims $(n=432), 5.2 \%$ are only perpetrators $(n=79)$, and $0 \%$ are only victims. On the basis of these results, future analyses will not focus on the perpetrators/victims' perspective, but on the form severity and frequency of violence, especially physical assault and psychological aggression. Considering each item of 253 the CTS2S separately, the prevalence rates are presented in table 1 for minor (M) and severe 254 (S) physical assault and psychological aggression.

Table 1. Prevalence for each item of physical assault and psychological aggression subscales.

\begin{tabular}{llllllll}
\hline & \multicolumn{2}{l}{$\begin{array}{l}\text { Total } \\
\text { (n=1532) }\end{array}$} & \multicolumn{2}{l}{$\begin{array}{l}\text { Women } \\
(\mathrm{n}=1238)\end{array}$} & \multicolumn{2}{l}{$\begin{array}{l}\text { Men } \\
(\mathrm{n}=294)\end{array}$} \\
\hline Physical assault & $\%$ & $\mathrm{~N}$ & $\%$ & $\mathrm{~N}$ & $\%$ & $\mathrm{~N}$ \\
\hline Victim - Sprain, bruise, or small cut (M) & 6.8 & 104 & 6.5 & 81 & 7.8 & 23 \\
Perpetrator - Sprain, bruise, or small cut (M) & 5.8 & 88 & 4.9 & 62 & 8.9 & 26 \\
Perpetrator - To push, shove, or slap (M) & 1.8 & 28 & 1.9 & 24 & 1.4 & 4 \\
Victim - pushed, shoved, or slapped (M) & 2.3 & 35 & 1.9 & 24 & 3.8 & 11 \\
Perpetrator - To punch or kick or beat-up (S) & 0.3 & 5 & 0.2 & 3 & 0.7 & 2 \\
Victim - Punched or kicked or beat-up (S) & 0.5 & 8 & 0.2 & 4 & 1.4 & 4 \\
Victim - To neeed to see a doctor (S) & 0.4 & 6 & 0.3 & 4 & 0.7 & 2 \\
Perpetrator - To send to see a doctor (S) & 0.5 & 8 & 0.3 & 4 & 1.4 & 4 \\
\hline Psychological aggression & & & & & & & \\
\hline Perpetrator - To insult or swore or shout or yel (M) & 30 & 460 & 31.8 & 394 & 22.5 & 66 \\
Victim - Insulted or swore or shouted or yelled (M) & 27.5 & 421 & 28 & 347 & 25.3 & 74 \\
Perpetrator - To destroyed something (S) & 0.9 & 14 & 0.9 & 12 & 0.7 & 2 \\
Victim - Have something destroyed (S) & 1.1 & 17 & 1.0 & 13 & 1.4 & 4 \\
\hline Note. (M)=Minor. (S)=Severe. & & & & & &
\end{tabular}

Second, lockdown-related, mental health and intimate partner variables are considered. Means and standard deviations for proximity to contamination, living environment, time at home, social contacts, couple duration, uncertainty-related aggression, anxiety, depression, 
258 intolerance of uncertainty, physical assault and psychological aggression, as well as internal 259 consistency and Spearman's correlations between these variables, are shown in Table 2. 
Table 2. Spearman's correlations, descriptive statistics and internal consistency

\begin{tabular}{|c|c|c|c|c|c|c|c|c|c|c|c|c|c|}
\hline & 1. & 2. & 3. & 4. & 5. & 6. & 7. & 8. & 9. & 10. & 11. & $M$ & SD \\
\hline 1. Prox. & 1 & & & & & & & & & & & .93 & 1.68 \\
\hline 2. Envi. & -.02 & 1 & & & & & & & & & & 5.57 & 1.77 \\
\hline 3. Home & -.03 & -.01 & 1 & & & & & & & & & 1.10 & .62 \\
\hline 4. Cont. & $.10 * *$ & $.07 * *$ & $-.05^{*}$ & 1 & & & & & & & & 16.49 & 3.76 \\
\hline 5. Couple & $-.06^{*}$ & $.37 * *$ & $.08 * *$ & -.04 & 1 & & & & & & & 3.62 & 1.04 \\
\hline 6. Agress. & .04 & $-.07 * *$ & .01 & $.06^{*}$ & $-.07 * *$ & 1 & & & & & & 2.76 & 1.25 \\
\hline 7. Anx. & .04 & $-.10 * *$ & -.03 & $.10 * *$ & $-.16 * *$ & $.35^{* *}$ & 1 & & & & & 6.75 & 3.85 \\
\hline 8. Dep. & .02 & $-.13 * *$ & $.10 * *$ & $-.07 * *$ & $-.06 *$ & $.30 * *$ & $.52 * *$ & 1 & & & & 7.42 & 3.54 \\
\hline 9. Uncert. & -.01 & $-.14 * *$ & .04 & .03 & $-.15^{* *}$ & $.49 * *$ & $.50 * *$ & $.40 * *$ & 1 & & & 6.62 & 1.97 \\
\hline 10. Phys. & .03 & $-.05 *$ & .03 & .01 & $-.08 * *$ & $.20 * *$ & $.14^{* *}$ & $.16^{* *}$ & $.15^{* *}$ & 1 & & 8.25 & 1.05 \\
\hline 11. Psycho. & $.06^{*}$ & $-.09 * *$ & .03 & .04 & $-.11 * *$ & $.34^{* *}$ & $.20 * *$ & $.22 * *$ & $.16 * *$ & $.31 * *$ & 1 & 4.83 & 1.44 \\
\hline
\end{tabular}

Note. Prox. = Proximity to contamination. Envi. $=$ Living environment. Home $=$ Time spent at home. Cont. = Social contacts. Couple $=$ couple duration. Agress. $=$ uncertainty-related aggression. Anx. = Anxiety. Dep. = Depression. Uncert. = Intolerence to Uncertainty. Phys. = Physical assault. Psycho. = Psychological aggression. ${ }^{*} p<.05 .{ }^{* *} p<.001$. 
260 Cronbach's alphas are good to high. Physical assault and psychological aggression are 261 significantly positively related to aggression associated with uncertainty, anxiety, depression, 262 and intolerance of uncertainty, and significantly negatively associated to living environment 263 and couple duration. Only psychological aggression is positively associated to proximity of 264 contamination.

\subsection{Group comparisons}

266 Cross-tables and Chi-square tests were run to identify prevalence rates and assess the gender 267 differences between physical assault, psychological aggression and increased violence (Table 3). The prevalence of physical assault is significantly higher in men, whereas the prevalence of psychological aggression is significantly higher in women. Men report significantly more increased violence during lockdown.

271 As group sizes were unequal and homogeneity of variance is generally not assumed ( $\mathrm{p}<.001)$,

272 the nonparametric equivalent of the independent samples t-test was conducted to compare 273 women and men on metric variables of interest (Table 2). Results of the Mann-Whitney U test 274 are also shown in Table 1. Women are found to be more anxious and more intolerant of 275 uncertainty. No difference between men and women was found for depression.

Table 3. Prevalence and gender differences of intimate partner violence behaviors.

\begin{tabular}{|c|c|c|c|c|c|c|c|c|c|}
\hline & \multicolumn{2}{|c|}{$\begin{array}{l}\text { Total } \\
(n=1532)\end{array}$} & \multicolumn{2}{|c|}{$\begin{array}{l}\text { Women } \\
(n=1238)\end{array}$} & \multicolumn{2}{|c|}{$\begin{array}{l}\text { Men } \\
(n=294)\end{array}$} & \multirow[t]{2}{*}{$X^{2}(d l=1)$} & \multirow[t]{2}{*}{$\mathrm{p}$} & \multirow[t]{2}{*}{ Phi } \\
\hline & $\%$ & $\mathrm{~N}$ & $\%$ & $\mathrm{~N}$ & $\%$ & $\mathrm{~N}$ & & & \\
\hline Physical assault & 9.2 & 140 & 8.4 & 104 & 12.3 & 36 & 4.27 & .03 & .05 \\
\hline Psychological aggression & 33.8 & 517 & 35.2 & 435 & 28.0 & 82 & 5.49 & .01 & -.06 \\
\hline \multirow[t]{2}{*}{ Increased violence } & 3.6 & 55 & 2.8 & 35 & 6.8 & 20 & 19.38 & .001 & .11 \\
\hline & $M$ & SD & M & SD & $M$ & SD & $U$ & $\mathrm{p}$ & \\
\hline Anxiety & 6.75 & 3.85 & 6.98 & 3.85 & 5.73 & 3.59 & 146202 & $<.001$ & \\
\hline Depression & 7.42 & 3.54 & 7.49 & 3.58 & 7.10 & 3.31 & 168932 & .05 & \\
\hline Uncertainty & 6.62 & 1.97 & 6.82 & 1.88 & 5.75 & 2.11 & 129355 & $<.001$ & \\
\hline
\end{tabular}


Also, differences between participants living with children during confinement and those who were not have been assessed through the Mann-Whitney U test. Results demonstrate that both groups do not differ concerning anxiety $(\mathrm{U}=301140.00, \mathrm{p}=.29)$, depression $(\mathrm{U}=294049.00$, $\mathrm{p}=.81)$, intolerance of uncertainty $(\mathrm{U}=279033.50, \mathrm{p}=.12)$, physical $(\mathrm{U}=290379.50, \mathrm{p}=.75)$ and psychological ( $\mathrm{U}=303254.00, \mathrm{p}=.11)$ violence. Therefore, this variable will not be included in the following models.

\subsection{Mediation Models}

To test the indirect effect of anxiety (M1) and depression (M2) in the relationship between intolerance of uncertainty (X) and physical assault (model 1) and psychological aggression (model 2) (Y), mediation models with multiple mediators were conducted (Model 4 of PROCESS macro) [70, 71]. As shown in table 4, anxiety and depression significantly mediate the relationship between intolerance of uncertainty and physical assault and psychological aggression. Because intolerance of uncertainty no longer affects violence after mediators have been included, both mediations are complete.

Table 4. Mediation Analyses with Multiple Mediators

\begin{tabular}{|c|c|c|c|c|c|c|c|}
\hline Variables & & Effect & $\begin{array}{l}\text { (boot) } \\
S E\end{array}$ & $t$ & $p$ & $\begin{array}{l}\text { (boot) } \\
\text { LLCl }\end{array}$ & $\begin{array}{l}\text { (boot) } \\
\text { ULCl }\end{array}$ \\
\hline Model 1 & \multicolumn{7}{|c|}{ DV $=$ Physical Assault } \\
\hline$y=$ Physical Assault & Total effect of $x$ on $y$ & .06 & .01 & 4.94 & $<.001$ & .0403 & .0933 \\
\hline$x=$ Uncertainty & Direct effect of $x$ on $y$ & .01 & .01 & .50 & .61 & -.0227 & .0384 \\
\hline $\mathrm{m}=$ All mediators & Indirect effect of $x$ on $y$ & .06 & .01 & & & .0298 & .0958 \\
\hline $\mathrm{m}=$ Anxiety & & .03 & .01 & & & .0099 & .0629 \\
\hline $\mathrm{m}=$ Depression & & .02 & .01 & & & .0104 & .0414 \\
\hline Model 2 & & \multicolumn{6}{|c|}{ DV = Psychological Aggression } \\
\hline$y=$ Psychol Violence & Total effect of $x$ on $y$ & .12 & .01 & 6.45 & $<.001$ & .0827 & .1548 \\
\hline$x=$ Uncertainty & Direct effect of $x$ on $y$ & .02 & .02 & .87 & .38 & -.0228 & .0596 \\
\hline $\mathrm{m}=$ All mediators & Indirect effect of $x$ on $y$ & .10 & .01 & & & .0718 & .1312 \\
\hline$m=$ Anxiety & & .05 & .01 & & & .0308 & .0891 \\
\hline $\mathrm{m}=$ Depression & & .04 & .01 & & & .0226 & .0602 \\
\hline
\end{tabular}

Note. $\mathrm{SE}=$ Standard Error; $\mathrm{LLCl}=$ Lower Limit of Confidence Interval; $\mathrm{ULCl}=$ Upper Limit of Confidence Interval. Observations with missing values were removed from the analysis. 


\subsection{Moderated Mediation Models}

291

292

As a gender difference has been demonstrated for many variables, it has been included in the model. To test the indirect effect of intolerance of uncertainty (IV) on physical assault and psychological aggression (DV) through anxiety and depression (M) moderated by gender (W), moderated mediation (moderator $\mathrm{x}$ mediator interaction) models with multiple mediators were conducted (Model 14 of PROCESS macro) [70, 71]. Our results demonstrate that gender does not significantly moderate the mediation models for either model: (model 3) the indirect effect of intolerance of uncertainty to physical assault through anxiety (Index $=.01$, BootSE $=.02$, BootLLCI=-.03, BootULCI=.07), the indirect effect of intolerance of uncertainty to physical assault through depression $($ Index $=.01$, BootSE=.02, BootLLCI=-.01, BootULCI=.06); (model 4) - the indirect effect of intolerance of uncertainty to psychological aggression through anxiety $(\operatorname{Index}=.01$, BootSE $=.03$, BootLLCI=-.05, BootULCI=.08), the indirect effect of intolerance of uncertainty to psychological aggression through depression $(\operatorname{Index}=.01$, BootSE $=.02$, BootLLCI=-.04, BootULCI=.05). Therefore, anxiety and depression completely mediate the relationship between intolerance of uncertainty and physical assault and psychological aggression for both men and women.

\section{Discussion}

As containment measures related to the COVID-19 crisis were announced in March in Europe and Canada, Since then, an increasing number of published peer-reviewed studies are analyzing IPV rates in light of the pandemic $[25,26,27]$. Our study is one of those early studies that evaluate violence between partners during confinement into the community to assesses the association between lockdown conditions and mental health, and that allowing us to identify avenues for intervention and prevention. 
During the confinement period, 33\% of the participants had experienced at least one form of psychological or physical violence within their couples after 4 weeks, without taking sexual violence into account. However the percentage of severe physical and psychological violence cases among participants was very low (victimization of severe physical assault [punched, kicked or beaten by partner] was $0.5 \%$ and victimization of severe psychological aggression: $2 \%$ ). These results are not surprising and represent only one facet of violence in couples that do not or only partially cover those targeted in the prevention and emergency assistance measures developed during the COVID-19 pandemic. Indeed, when studying violence in couples, it is important to take into account the type of sample, as different degrees of IPV (Intimate Terrorism and Situational Couple Violence) may be present depending on the type of sample [33]. Our online study conducted during containment allowed for rapid recruitment from the entire population, to include a large amount of variability, which makes it ideal for studying IPV. But the online study of non-clinical samples identified minor violence in couples, and more often reciprocal violence. As a type of selection bias, perpetrators and victims of intimate terrorism-type violence should be less likely to respond to these online surveys as victims should be prohibited from responding and perpetrators should be unlikely to report their own actions. Access to these surveys requires the use of clinical samples distributed in shelters, hospitals or among the police, which was not possible during the period of confinement [36]. According to extensive studies, our results reflect that $84.5 \%$ of perpetrators were also victims of violence, and among victims of IPV, all were perpetrators. These associations may reflect the use of psychological and physical aggression in the context of situational couple altercations $[30,32]$. Our data do not allow us to determine the context, intentions and reactions of the perpetrator and victim partners, and although our results seem to reflect situational violence, 
approaches using interviews are needed to deeper into the types of violence experienced during periods of confinement and deconfinement Covid 19.

It should be noted that women are significantly more involved in psychological assaults, and men in physical assaults. However, men reported that involvement in IPV significantly increased during the lockdown. It is possible that the context of confinement may have increased the amount of time spent at home, increased tensions, conflict and violence for men, but it is also possible that men may have identified and experienced these experiences as violence because of the confinement when it may have appeared trivialized/normalized before. Previous studies have shown that an increase in the intensity and seriousness of violence can lead a victim to become aware of the violence $[72,73]$. Our results would suggest that the fact of being confronted with violence for men and being confined at home and in couples without other social living spaces could lead to an identification and awareness of this violence. Also, those in the youngest relationships are likely to experience physical and psychological violence during confinement, as well as to present symptoms of psychological distress (anxiety and depressive symptoms) associated with such violence, and intolerance of uncertainty perceived as generating, among other things, aggressiveness towards the partner (see correlations table 2). These findings highlight that young couples are more at risk in terms of physical and psychological violence, finding already highlighted in previous research [74] and psychological distress in confinement [11]. Couples in older relationships may be better able to withstand confinement and provide supportive and safe environments for their partners to cope with stress and uncertainty generated by the pandemic and confinement. couples within their homes, thereby increasing the amount of time couples spend together on a daily basis, while decreasing the possibilities for contact and social relations with the outside 
world. Interestingly, our study shows that work at home or absence from work, therefore being more present at home, is significantly associated with depressive symptoms, but is not correlated with intimate partner violence. In contrast, results reveal that physical and psychological violence is associated with a smaller living spaces that lack a garden or terrace. Since housing is an indicator of a person's socio-economic level, it can be assumed that socially disadvantaged couples have been more affected by confinement. Indeed, a smaller living environment is also associated with the presence of anxiety, depression, intolerance of uncertainty and aggression related to uncertainty (see correlations). Although it is certainly the case that middle class and affluent families also experience cases of domestic violence, studies consistently indicate that as the financial status of a family increases, the likelihood of domestic violence decreases $[75,76]$. Couples experiencing financial and family stressors during the pandemic have likely an increase of the number of arguments and conflicts, and of the common couple violence during sustained social isolation and physical proximity, particularly among young and newly formed intimate relationships [17, 26]. Sharma and Borah (2020) consider that the increase of domestic violence during the Covid-19 pandemic is an indirect driver of economic and social crisis [77].

The psychological impact of containment and the COVID-19 pandemic crisis on the mental health of the population is now demonstrated, with higher rates of anxiety and depression observed, which are linked to, among other things, IU [7, 11, 12, 78]. Pandemic crises sow uncertainty which can last for a long time; intolerance of uncertainty is a risk factor for the mental health of the population [3, 4]. Furthermore, poor mental health including anxiety and depression is a risk factor for intimate partner violence IPV perpetration and victimization [42, 43, 44, 45, 46] among men and women. 
Recent research suggests that IU may be an important contributor to the anxiety disorders and depression's symptoms. This is the first study to examine whether IU predicts intimate partner violence in the context of confinement, and if mental health (anxiety and depression) could explicate and participate to this relationship. Interestingly, our study demonstrates that intolerance of uncertainty predicts the perpetration and victimization of physical and psychological violence in confined couples, by increasing depressive and anxiety symptoms for both men and women. Individuals who are intolerant of uncertainty are more at risk of feeling anxious or depressed and are therefore more likely to experience IPV. IU alone does not appear to explain by itself the increase in the rates of this type of violence. Rather, it seems to be because individuals experience or are vulnerable to anxiety and depression related to uncertainty that rates of intimate partner physical and psychological violence increase (Complete mediation). This phenomenon would be relevant for both women and men (nonsignificant moderated mediation). These major findings are a reminder that depression can increase the risk of violence and involvement in verbal conflicts [79]. They also highlight that depression and anxiety for both men and women are real risk factors for physical and psychological violence during the confinement.

Our study, conducted in the midst of a pandemic lockdown, incorporated intolerance of uncertainty into models of psychological and physical violence. Deconfinement will give rise to even more uncertainty than the confinement period, as subjects will no longer be required to remain in their homes and the rules on social interaction patterns and risks will be less clear. It is therefore important to incorporate this variable into our psychological models. Our results show, however, that reducing uncertainty will not directly decrease the risk of violence, nor will it directly increase it, but for subjects in whom uncertainty is anxiety-inducing and depressogenic, intolerance of uncertainty may increase and/or lead to violence. 
These results underscore the importance of paying attention to the mental health of individuals in studies of IPV, especially during periods of confinement and deconfinement, This is especially significant if individuals are suffering from depression as it is a factor of recidivism [80]. Our study has made it possible to highlight the existence of physical and psychological IPV, which can affect both women and men living in intimate relationships. While public policies during confinement have focused on violence against women and on severe violence, our survey highlights the need to also take into account minor violence within couples, and violence perpetrated and suffered by women and men [81]. IPV in times of crisis and the associated mental health factors require a combination of social, medical and legal responses. As informal contacts are the main detection and support system, community-based initiatives and public media should be used to raise awareness of the increased risk of IPV during the pandemic $[21,82]$. Governments need to do more to alert the public to additional stressors and communicate about coping strategies [27]. A proactive approach focusing on well-being, hopefulness or self-efficacy can be useful during the Covid-19 period and help reduce the social crisis [77]. Given the impact that pandemic may have on mental health and the highlighted links to partner violence, health professionals need to pay particular attention to the mental stability of their patients, intervening to reduce the exacerbation of co-morbid psychiatric disorders and thus reduce the potential risk of violence [82]. In a time of reaction, developing protocols and training frontline professionals (police officers, psychologists, doctors...) in IPV screening procedures and mental health risk factors in times of crisis could help to better identify people at risk [49, 83].

\section{Strength and limitations}

The present research has several strengths, such as the large sample, recruitment across several countries, the diversity and completeness of studied variables, and the solidity and relevance of tested statistical models. This is one of the first studies to evaluate intimate partner violence, 
including variables associated with confinement conditions, depression, anxiety and intolerance to uncertainty, and highlighting an innovative model. The first limit is that women are overrepresented. Gender has been taken into account in all analyses to neutralize this problem. Also, we use a non-validated 2-items version of the IU scale. Another limit is that, as mentioned by Kaukinen [17], the samples from self-report data may not include all women who are victims of the most severe types of IPV or those who are victims of COVID-19 disease. Finally, our study evaluated psychological and physical violence on the basis of CTS2, what does not measure the consequences or the causes of the assault (such as the desire to dominate), or dynamics of violence. Although the CTS2 could be criticized for being reductionist in its sole focus on the presence of an act, and ignoring the context in which the act took place, it does afford measurement of the form, severity and frequency of different acts in our study "during lockdown" [84]. However, futures researches need for careful joint analyses of self-report survey data, estimates from law enforcement agencies, and clinical data during and after COVID-19. This will allow to tap diverse types of intimate partner abuse and also explore the way in which COVID-19 disease progression may place women and men at further risk for physical violence, emotional and financial abuse, and coercive control [17]. Subsamples should also be required from vulnerable/precarious populations such as those in shelters, hospitals and from the police, namely population with little access to online surveys. Future research is needed to highlight the intimate partner violence process in at-risk populations, especially mental health-related and crisis associated risks to develop intervention and assistance strategies during crisis and post-crisis periods, such as the one we are experiencing with COVID19.

\section{Conclusion}

During the COVID-19 epidemic, people faced a sense of uncertainty that affected levels of anxiety and depression, and the risk of IPV. First, clear and consistent information regarding 
477 Couple: couple duration

\section{Conflict of interest}

\section{Abbreviations}

Anx: Anxiety.

Cont: Social contacts

the disease and management plan should be provided to everyone so as to avoid panic, confusion and to reduce uncertainty [85]. Secondly, there is a need for programs to prevent IPV of varying severity, among youth, men and women, and especially among those who are psychologically fragile in the context of the uncertainty caused by the pandemic, and particularly for socially and psychologically vulnerable people. In addition, It is important to strengthen psychological first aid that is a crucial early intervention that focuses on mental health of the population by providing psychosocial support during outbreaks like COVID-19 $[85,86]$. It is also necessary to make all front-line medical and psychological professionals aware of the existence of risk of IPV so that they integrate it into their assessment and interventions with patients. These early intervention could offer help to both victims and perpetrators and stop the escalation and/or installation of more severe IPV. Finally, it seems appropriate to continue these interventions after confinement because the uncertainties that the population will face could increase.

Authors declare that they have no conflict of interest.

Agress: uncertainty-related aggression

CTS2S or CTS2: Short-form Revised Conflict Tactic Scales

479 Dep: Depression. 
481 HAD: Hospital Anxiety and Depression scale

482 Home: Time spent at home

483 M: Minor

$484 \quad \mathbf{M}(\mathbf{1 , 2})$ : Mediator

485 IPV: Intimate Partner Violence

486 IRB: Institutional Review Board

487 IT: intimate terrorism

488 IU or Uncert: intolerance of uncertainty

489 IUS: Intolerance of Uncertainty Scale

490 LLCI: Lower Limit of Confidence Interval

491 Phys: Physical assault

492 Prox: Proximity to contamination

493 Psycho: Psychological aggression

494 S: Severe

495 SCV: situational couple violence

496 SE: Standard Error

497 SPSS: Statistical Package for the Social Sciences

498 ULCI: Upper Limit of Confidence Interval

499 W: Moderation

500 WHO: World Health Organization 


\section{Declarations}

504

\section{Acknowledgements}

505

506

507

508

509

510

511

512

513

514

515

516

517

518

519 Not applicable. manuscript.

\section{Funding}

Not applicable

\section{Authors' contributions}

FG designed the research and the study protocol. ES organized the database, analyzed the data, FG wrote the draft of manuscript. FG, ES and AD contributed to and approved the

\section{Availability of data and materials}

The datasets used and/or analysed during the current study are available from the corresponding author on reasonable request (fabienne.glowacz@uliege.be)

\section{Ethics approval and consent to participate}

The methodology has been approved by the IRB of the University of Liège, the Ethics

Committee Faculty of Psychology. All participants provided written informed consent.

\section{Consent for publication}


521 The authors declare that they have no competing interests.

\section{Author Details.}

$523{ }^{123}$ Department of Psychology - Adaptation, Resilience and Change Research Unit (ARCh)

524 University of Liège- Place des Orateurs, 1-Liège, Belgium. Correspondence to 525 fabienne.glowacz@uliege.be

\section{References}

526 [1] WHO. Understanding and Addressing Violence Against Women. Geneva World Health Organization. 2012. http://apps.who.int/iris/bitstream/10665/77432/1/WHO_RHR_12.36_eng.pdf Accessed july 2020

[2] Carleton RN, Mulvogue MK, Thibodeau MA, Mccabe RE, Antony MM, Asmundson, GJ.G. Journal of Anxiety Disorders Increasingly certain about uncertainty : Intolerance of uncertainty across anxiety and depression. Journal of Anxiety Disorder. 2012;26:468-479. https://doi.org/10.1016/j.janxdis.2012.01.011

534

[3] Freeston MH, Tiplady A, Mawn L, Bottesi G, Thwaites S. Towards a model of uncertainty distress in the context of Coronavirus (Covid-19). Preprints. 2020; DOI: 10.31234/osf.io/v8q6m

[4] Mertens G, Gerritsen L, Duijndam S, Elske S, Engelhard IM. Fear of the coronavirus (COVID-19): Predictors in an online study conducted in March 2020. Journal of Anxiety Disorder. 2020; https://doi.org/https://doi.org/10.1016/j.janxdis.2020.102258

[5] Sankar R, Robinson L, Honey E, Freeston M. ' We know intolerance of uncertainty is a transdiagnostic factor but we don' $t$ know what it looks like in everyday life ': A s ystematic review of intolerance of uncertainty behaviours . Clinical Psychology Forum 

august-2017.html

[6] Sim K, Chua HC. The psychological impact of SARS: a matter of heart and mind.

548 [7] Brooks SK, Webster RK, Smith LE, Woodland L, Wessely S, Greenberg N, Rubin GJ. Rapid Review The psychological impact of quarantine and how to reduce it : rapid review of the evidence. The Lancet. 2020;395(10227):912-920. https://doi.org/10.1016/S0140$\underline{6736(20) 30460-8}$

552

553

554

555

556

[8] Hossain MM, Sultana A, Purohit N. Mental health outcomes of quarantine and isolation for infection prevention: A systematic umbrella review of the global evidence. Epidemiol Health. 2020; DOI:10.4178/epih.e2020038

[9] Glowacz F, Schmits E. Psychological distress during the COVID-19 lockdown: the young adults most at risk. Psychiatry research. 2020; 293(113486).

\section{https://doi.org/10.1016/j.psychres.2020.113486}

[10] Sharma A, Pillai DR, Lu M, Doolan C, Leal J, Kim J, Hollis A. Impact of isolation precautions on quality of life : a meta-analysis. Journal of Hospital Infection. 2020;105:35-42. https://doi.org/10.1016/j.jhin.2020.02.004

[11] Cao W, Fang Z, Hou G, Han M, Xu X, Dong J. The psychological impact of the COVID-19 epidemic on college students in China. Psychiatry Research. 2020;287(112934). https://doi.org/10.1016/j.psychres.2020.112934

[12] Zhang SX, Wang Y, Rauch A, Wei F. Health, distress and life satisfaction of people in China one month into the COVID-19 outbreak. Psychiatry Research. 2020;288(112958). https://doi.org/10.1016/j.psychres.2020.112958. http://dx.doi.org/10.2139/ssrn.3555216 
[13] Glowacz F, Schmits E. Psychological distress during the COVID-19 lockdown: the young adults most at risk. Psychiatry research. 2020;293(113486). https://doi.org/10.1007/s11469-020-00432-8

[14] Lorant V, Smith P, Van den Broeck K, Nicaise P. Psychological distress associated with the COVID-19 pandemic and suppression measures during the first wave in Belgium. BMC psychiatry. 2021;21(1):1-10. https://doi.org/10.1186/s12888-021-03109-1

[15] Varma P, Junge M, Meaklim H, Jackson ML. Younger people are more vulnerable to stress, anxiety and depression during COVID-19 pandemic: A global cross-sectional survey. Progress in Neuro-Psychopharmacology and Biological Psychiatry. 2021; 109(110236). https://doi.org/10.1016/j.pnpbp.2020.110236

[16] Campbell AM. An increasing risk of family violence during the Covid-19 pandemic: Strengthening community collaborations to save lives. Forensic Science International: Reports. 2020;2(100089). https://doi.org/10.1016/j.fsir.2020.100089

[17] Kaukinen C. When Stay-at-Home Orders Leave Victims Unsafe at Home : Exploring the Risk and Consequences of Intimate Partner Violence during the COVID-19 Pandemic. American Journal of Criminal Justice. 2020;

https://doi.org/https://doi.org/10.1007/s12103-020-09533-5

[18] Bradbury-Jones C, Isham L. The pandemic paradox : The consequences of COVID-19 on domestic violence. Journal of Clinical Nursing. 2020;19:2047-2049. https://doi.org/10.1111/jocn.15296

[19] Mazza M, Marano G, Lai C, Janiri L, Sani G. Danger in danger : Interpersonal violence during COVID-19 quarantine. Psychiatry Research. 2020;289(113046). https://doi.org/10.1016/j.psychres.2020.113046

[20] Bruxelles Prévention \& Sécurité. Les violences intrafamiliales en Région de Bruxelles-Capitale en période de confinement. Focus de l'Observatoire. 2020;1. 
https://bps-bpv.brussels/fr/focus-1-les-violences-intrafamiliales-en-region-de-bruxelles-

\section{capitale-en-periode-de-confinement}

[21] van Gelder N, Peterman A, Potts A, O’Donnell M, Thompson K, Shah N, OerteltPrigione S. COVID-19: Reducing the risk of infection might increase the risk of intimate partner violence. EClinicalMedicine. 2020; doi:10.1016/j.eclinm.2020.100348

[22] Guenfound I. French women use code words at pharmacies to escape domestic violence during coronavirus lockdown. ABC News. 2020.

https://abcnews.go.com/International/french-women-code-words-pharmacies-escapedomestic-violence/story?id=69954238. Accessed July 2020

[23] Davies S, Batha E. Europe braces for domestic abuse 'perfect storm' amid coronavirus lockdown. Thomas Reuters Foundation News. 2020.

https://news.trust.org/item/20200326160316-710uf. Accessed July 2020

[24] Usher K, Bhullar N, Durkin J, Gyamfi N, Jackson D. Family violence and COVID-19: Increased vulnerability and reduced options for support. International Journal of Mental Health Nursing. 2020;29:549-552. doi: 10.1111/inm.12735

[25] McLay MM. When "Shelter-in-Place” Isn't Shelter That's Safe: A Rapid Analysis of Domestic Violence Case Differences During the COVID-19 Pandemic and Stay-at-Home Orders. MedRxiv. 2020. https://doi.org/10.1101/2020.05.29.20117366

[26] Hamadani JD, Hasan MI, Baldi AJ, Hossain SJ, Shiraji S, Bhuiyan MSA, Mehrin SF, Fisher J, Tofail F, Tipu MU, Grantham-McGregor S, Biggs BA, Braat S, Pasricha SR. Immediate impact of stay-at-home orders to control COVID-19 transmission on socioeconomic conditions, food insecurity, mental health, and intimate partner violence in Bangladeshi women and their families: an interrupted time series. The Lancet Global Health. 2020;8(11):1380-1389. https://doi.org/10.1016/S2214-109X(20)30366-1 
Linear Moderated Mediation. Multivariate Behavioral Research. 2015;50(1):1-22. https://doi.org/10.1080/00273171.2014.962683

619

620

621

622

623

624

625

626

627

628

629

630

631

632

633

634

635

636

637

638

639

640

641

[28] Cannon CE, Ferreira R, Buttell F, First J. COVID-19, Intimate Partner Violence, and Communication Ecologies. American Behavioral Scientist. 2021; https://doi.org/10.1177/0002764221992826

[29] Bonnet F. Violences conjugales, genre et criminalisation: synthèse des débats américains. Revue française de sociologie. 2015;2(56):357-383. ISSN 0035-2969

[30] Ali AP, Dhingra K, Mcgarry J. Aggression and Violent Behavior A literature review of intimate partner violence and its classifications. Aggression. 2016;31:16-25.

https://doi.org/10.1016/j.avb.2016.06.008

[31] Archer J. Sex Differences in Aggression Between Heterosexual Partners : A MetaAnalytic Review. Psychological Bulletin. 2000;126(5):651-680. https://doi.org/10.1037/0033-2909.126.5.651

[32] Capaldi DM, Knoble NB, Shortt JW, Kim HK. A Systematic Review of Risk Factors for Intimate Partner Violence. Partner Abuse. 2012;3(2):231-281.

https://doi.org/http://dx.doi.org/10.1891/1946-6560.3.2.231

[33] Capaldi DM, Low S, Tiberio SS, Shortt JW. Intimate Partner Violence Across the Lifespan : Dyadic Theory and Risk and Protective Factors. In: Geffner R, White JW, Hamberger LK, Rosenbaum A, Vaughan-Eden V, Vieth VI, editors. Handbook of Interpersonal Violence across the Lifespan. Springer Nature; 2019. p. 1-25

[34] Johnson MP. Patriarchal Terrorism and Common Couple Violence : Two Forms of Violence against Women. Journal of Marriage and Family. 1995;57(2): 283-294. http://www.jstor.com/stable/353683

[35] Johnson MP, Leone, JM. The Differential Effect of Intimate Terrorism and Situational Couple Violence. Journal of Family Issues. 2005;26(3):322-349. 
643

644

645

646

647

648

649

650

651

652

653

654

655

656

657

658

659

660

661

662

663

664

665

666

[36] Johnson MP. Conflict and Control in Domestic Violence. Gender Symmetry and Asymmetry in Domestic Violence. Violence Against Women. 2006;12(11):1003-1018. https://doi.org/10.1177/1077801206293328

[37] Love HA, Spencer CM, May SA, Mendez M, Stith SM. Perpetrator Risk Markers for Intimate Terrorism and Situational Couple Violence : A Meta-Analysis. Trauma, Violence, \& Abuse. 2018;21(5):922-931. https://doi.org/10.1177/1524838018801331

[38] O'Leary DK., Maiuro RD. Psychological abuse in violent domestic relations. New York, NY: SpringerPublishing Co; 200.

[39] Glowacz F, Courtain A. Violences au sein des relations amoureuses des adolescents et jeunes adultes : une réalité à ne pas négliger. Champ Pénal. 2017;14.

https://doi.org/10.4000/champpenal.9582

[40] Courtain A, Glowacz F. Exploration of dating violence and related attitudes among adolescents and emerging adults. Journal of interpersonal violence. 2018; https://doi.org/10.1177/0886260518770185

[41] Martín-fernández M, Gracia E, Lila M. Psychological intimate partner violence against women in the European Union : a cross-national invariance study. BMC Public Health. 2019;19(1739):1-11. https://doi.org/https://doi.org/10.1186/s12889-019-7998-0

[42] Dziewa A, Glowacz F. Getting out from Intimate Partner Violence: Dynamics and Processes. A Qualitative Analysis of Female and Male Victims' Narratives. Journal of family violence. 2021:1-14. https://doi.org/10.1007/s10896-020-00245-2

[43] Shorey RC, Febres J, Brasfield H, Stuart GL. The Prevalence of Mental Health Problems in Men Arrested for Domestic Violence. Journal of Family Violence. 2012;27:741-748. https://doi.org/10.1007/s10896-012-9463-Z

[44] Swan SC, Gambon LJ, Fields AM, Sullivan TP, Snow DL. Women Who Use Violence 
in Intimate Relationships : The Role of Anger, Victimization, and symptoms of posttraumatic stress and depression. Violence and Victims. 2005;20(3):267. DOI:

$$
\text { 10.1891/vivi.20.3.267 }
$$

[45] Spencer CM, Stith SM, Cafferky B. Risk markers for physical intimate partner violence victimization: A meta-analysis. Aggression and Violent Behavior. 2019;44:8-17. https://doi.org/10.1016/j.avb.2018.10.009

[46] Spencer C, Mallory AB, Cafferky BM, Kimmes JG, Beck AR, Stith SM. Mental Health Factors and Intimate Partner Violence Perpetration and Victimization : A MetaAnalysis. Psychology of Violence. 2019b;9(1):1-17. https://doi.org/10.1037/vio0000156

[47] Trevillion K, Oram S, Feder G, Howard LM. Experiences of Domestic Violence and Mental Disorders : A Systematic Review and Meta-Analysis. PLoS ONE. 2012;7(12). https://doi.org/10.1371/journal.pone.0051740

[48] Breet E, Seedat S, Kagee A. Posttraumatic Stress Disorder and Depression in Men and Women Who Perpetrate Intimate Partner Violence. Journal of Interpersonal Violence. 2019;34(10):2181-2189. https://doi.org/10.1177/0886260516660297

[49] Moreira DN, da Costa MP. The impact of the Covid-19 pandemic in the precipitation of intimate partner violence. International journal of law and psychiatry. 2020;71(101606). https://doi.org/10.1016/j.ijlp.2020.101606

[50] Lyons M, Brewer G. Experiences of intimate partner violence during lockdown and the COVID-19 pandemic. Journal of family violence. 2021:1-9. https://doi.org/10.1007/s10896-021-00260-x

[51] Zandifar A, Badrfam R. Iranian mental health during the COVID-19 epidemic What. Asian Journal of Psychiatry. 2020;51(101990). https://doi.org/10.1016/j.ajp.2020.101990

[52] Carleton RN. Into the unknown : A review and synthesis of contemporary models involving uncertainty. Journal of Anxiety Disorder. 2016;39:30-43. 


\section{https://doi.org/http://dx.doi.org/10.1016/j.janxdis.2016.02.007}

[53] Freeston MH, Rhéaume J, Letarte H, Dugas MJ, Ladouceur R. Why do people worry? Personality and individual differences. 1994;17(6):791-802. https://doi.org/10.1016/0191$\underline{8869(94) 90048-5}$

[54] Birrell J, Meares K, Wilkinson A, Freeston M. Toward a definition of intolerance of uncertainty: A review of factor analytical studies of the Intolerance of Uncertainty Scale. Clinical psychology review. 2011;31(7):1198-1208.

\section{https://doi.org/10.1016/j.cpr.2011.07.009}

[55] Dar KA, Iqbal N, Mushtaq A. Intolerance of uncertainty, depression, and anxiety: Examining the indirect and moderating effects of worry. Asian journal of psychiatry. 2017;29:129-133. https://doi.org/10.1016/j.ajp.2017.04.017

[56] Toro RA, Avendaño-Prieto BL, Vargas N. Transdiagnostic model of anxiety and depression according to the relationship with affect, intolerance of uncertainly, and anxiety sensitivity. Revista CES Psicología. 2019;13(1):140-152.

https://doi.org/10.21615/cesp.13.1.9

[57] Satici B, Saricali M, Satici, AS, Griffiths MD. Intolerance of Uncertainty and Mental Wellbeing : Serial Mediation by Rumination and Fear of COVID-19. International Journal of Mental Health and Addiction. 2020; https://doi.org/10.1007/s11469-020-00305-0

[58] del Valle MV, Andrés ML, Urquijo S, Yerro-Avincetto M, López-Morales H, CanetJurica L. Intolerance Of Uncertainty Over Covid-19 Pandemic And Its Effect On Anxiety And Depressive Symptoms. Revista Interamericana de Psicología/Interamerican Journal of Psychology. 2020;54(2):e1335. ISSN: 0034-9690

[59] Dodge KA. The structure and function of reactive and proactive aggression. In: Pepler DJ, Rubin KH, editors. The development and treatment of childhood aggression. Hillsdale, NJ: Lawrence Erlbaum. 1991. p. 201-218 
[60] Fracalanza K, Koerner N, Deschênes SS, Dugas MJ. Intolerance of Uncertainty Mediates the Relation Between Generalized Anxiety Disorder Symptoms and Anger. Cognitive Behaviour Theray. 2014;43(2):122-132.

\section{https://doi.org/10.1080/16506073.2014.888754}

[61] Sadeh N, Bredemeier K. Engaging in risky ans impulsive behaviors to alleviate distress mediates associations between intolerance of uncertainty ans externalizing psychopathology. Journal of Personality Disorders. 2019;33(2):456.

https://shop.bps.org.uk/publications/clinical-psychology-forum-no-296-august-2017.html

[62] Boswell JF, Thompson-hollands J, Farchione TJ, Barlow DH. Intolerance of Uncertainty: A Common Factor in the Treatment of Emotional Disorders. Journal of Clinical Psychology. 2013;69(6):630-645. https://doi.org/10.1002/jclp.21965

[63] Gentes EL, Ruscio AM. Clinical Psychology Review A meta-analysis of the relation of intolerance of uncertainty to symptoms of generalized anxiety disorder, major depressive disorder, and obsessive - compulsive disorder. Clinical Psychology Review. 2011;31:923-933. https://doi.org/10.1016/j.cpr.2011.05.001

[64] Rosser BA. Intolerance of Uncertainty as a Transdiagnostic Mechanism of Psychological Difficulties : A Systematic Review of Evidence Pertaining to Causality and Temporal Precedence. Cognitive Therapy Ans Research. 2019;43(5):438-463. https://doi.org/10.1007/s10608-018-9964-Z

[65] Zigmond AS, Snaith RP. The hospital anxiety and depression scale. Acta psychiatrica scandinavica. 1983;67(6):361-370. https://doi.org/10.1111/j.1600-0447.1983.tb09716.x

[66] Bjelland I, Dahl AA, Haug TT, Neckelmann D. The validity of the Hospital Anxiety and Depression Scale An updated literature review. Journal of Psychosomatic Research. 2002;52:69-77. https://doi.org/10.1016/S0022-3999(01)00296-3

[67] Straus MA, Douglas EM. The short form of the Revised Conflict Tactics Scales,and 
typologies for severity and mutuality. Violence and Victims. 2004;19:507-520. DOI:

744

745

746

747

748

749

750

751

752

753

754

755

756

757

758

759

760

761

762

763

764

765

766

[68] Preacher KJ, Hayes AF. SPSS and SAS procedures for estimating indirect effects in simple mediation models. Behavior research methods, instruments, \& computers. 2004;36(4):717-731. https://doi.org/10.3758/BF03206553

[69] Shrout PE, Bolger N. Mediation in Experimental and Nonexperimental Studies : New Procedures and Recommendations. Psychological Methods. 2002;7(4):422-445. https://doi.org/10.1037//1082-989X.7.4.422

[70] Hayes AF. An index and test of linear moderated mediation. Multivariate behavioral research. 2015;50(1):1-22. https://doi.org/10.1080/00273171.2014.962683

[71] Hayes AF. Introduction to mediation, moderation, and conditional process analysis: A regression-based approach. New York: The Guilford Press; 2018.

[72] Hayes AF. Partial, conditional, and moderated moderated mediation : Quantification, inference, and interpretation Quantification, inference, and interpretation. Communication Monographs. 2018;85(1):4-40. https://doi.org/10.1080/00273171.2014.962683

[73] Band-winterstein T, Eisikovits Z. Intimate Violence Across the Lifespan. Interpersonal, Familial ans Cross-Generational Perspectives. The Spring; 2014.

[74] Chang JC, Dado D, Hawker L, Mcneil M, Scholle SH, Cluss PA, Buranosky R, Slagel L, McNeil M, Scholle H. Understanding Turning Points in Intimate Partner Violence: factors and circumstances leading women victims toward change. Journal of Women's Health. 2010;19(2):251-259. https://doi.org/10.1089/jwh.2009.1568

[75] Kim H, Laurent H, Capaldi DM, Feingold A. Men's Aggression Toward Women : A 10-Year Panel Study. Journal of Marriage and Family. 2008;70:1169-1187.

https://doi.org/10.1111/j.1741-3737.2008.00558.x 
[76] Benson ML, Fox GL. When Violence Hits Home: How Economics and Neighborhood Play a Role, Research in Brief. U.S. Department of Justice Office of Justice Programs National Institute of Justice. 2004.

https://www.ncjrs.gov/App/Publications/abstract.aspx?ID=205004. Accessed September 2020

[77] Renzetti CM. Economic Stress and Domestic Violence. CRVAW Faculty Research Reports and Papers. 2009;1. https://uknowledge.uky.edu/crvaw_reports

[78] Fiorillo A, Gorwood P. The consequences of the COVID-19 pandemic on mental health and implications for clinical practice. European Psychiatry. 2020;63(1):1-2. https://doi.org/10.1192/j.eurpsy.2020.35

[79] Berg MT, Rogers EM, Liu W, Mumford EA, Taylor BG. The interpersonal context of depression and violent behavior: A social psychological interpretation. Aggressive Behavior. 2019;45:437-449. https://doi.org/10.1002/ab.21832

[80] Green K, Browne K. Personality Disorder Traits , Trauma , and Risk in Perpetrators of Domestic Violence. International Journal of Offender Therapy and Comparative Criminology. 2020;64(2-3):147-166. https://doi.org/10.1177/0306624X19826516

[81] Warburton E, Raniolo E. Domestic Abuse during COVID-19 - What about the boys? Psychiatry Research. 2020;291(113155).

\section{https://doi.org/https://doi.org/10.1016/j.psychres.2020.113155}

[82] Telles LE, Valença AM, Barros AJS, da Silva AG. Domestic violence in the COVID19 pandemic: A forensic psychiatric perspective. Revista Brasileira de Psiquiatria. 2020. https://doi.org/10.1590/1516-4446-2020-1060.

[83] Jarnecke AM, Flanagan JC. Staying safe during COVID-19: How a pandemic can escalate risk for intimate partner violence and what can be done to provide individuals with resources and support. Psychological trauma: theory, research, practice, and policy. 
793 [84] Chapman H, Gillespie SM. The Revised Conflict Tactics Scales (CTS2): a review of the properties, reliability, and validity of the CTS2 as a measure of partner abuse in community and clinical samples. Aggression and violent behavior. 2019;44:27-35. https://doi.org/10.1016/j.avb.2018.10.006

797 [85] Haider II, Tiwana F, Tahir SM. Impact of the COVID-19 Pandemic on Adult Mental 798 Health. Pakistan Journal of Medical Sciences. 2020;36(COVID19-S4). https://doi.org/10.12669/pjms.36.COVID19-S4.2756

800 [86] Shah K, Kamrai D, Mekala H, Mann B, Desai K, Patel R. Focus on Mental Health 801 During the Coronavirus (COVID-19) Pandemic: Applying Learnings from the Past $802 \quad$ Outbreaks. Cureus. 2020; doi: 10.7759/cureus.7405 


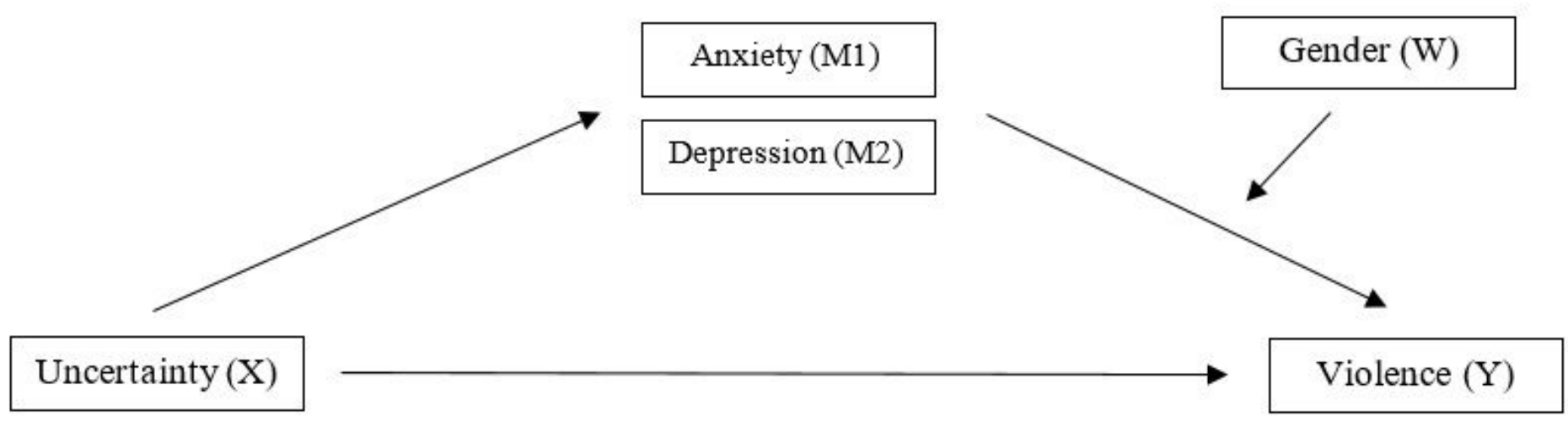

\section{Figure 1}

Moderated mediation models. Note. Distinct models have been tested: the indirect effect of anxiety (M1) and depression (M2) in the relationship between intolerance of uncertainty (X) and physical (model 1) and psychological (model 2) violence $(\mathrm{Y})$, according to gender $(\mathrm{W})$ (model 3 and model 4 ). 